\title{
Médicos pelo Brasil e as políticas de saúde para a Estratégia Saúde da Família de 1994 a 2019: caminhos e descaminhos da Atenção Primária no Brasil
}

\author{
Médicos pelo Brasil and the health policies for the Family Health Strategy from 1994 to 2019: \\ paths and deviations of Primary Care in Brazil
}

\section{Médicos pelo Brasil y las políticas de salud para la Estrategia Salud de la Familia de 1994 a 2019: caminos y descaminos de la Atención Primaria en Brasil}

\author{
Maria Inez Padula Anderson ${ }^{1}$ (D) \\ ${ }^{1}$ Universidade do Estado do Rio de Janeiro (UERJ). Rio de Janeiro, RJ, Brasil.
}

\section{Resumo}

No dia 1 de agosto de 2019, o presidente Bolsonaro e seu Ministro da Saúde lançam o Programa Médicos pelo Brasil como aquele que, segundo os mesmos, substituirá o Programa Mais Médicos. O propósito deste artigo é contribuir para uma análise desta mais recente proposta de política de saúde no âmbito da Atenção Primária à Saúde no contexto do Mais Médicos e das demais políticas de desenvolvimento e qualificação da ESF no país no período de 1994 a 2019.

Palavras-chave: Atenção Primária à Saúde, Estratégia Saúde da Família, Política de Saúde, Força de Trabalho em Saúde, Distribuição de Médicos

\begin{abstract}
On August 1, 2019, President Bolsonaro and his Minister of Health launched the Program Doctors throughout Brazil (Programa Médicos pelo Brasil) that will replace the Program More Doctors (Programa Mais Médicos). The purpose of this article is to contribute to an analysis of that latest primary care policy proposal in the context of the Program More Doctors and other development and qualification of the Family Health Strategy (FHS) in the country from 1994 to 2019.
\end{abstract}

Keywords: Primary Health Care, Health Family Strategy, Health Policy, Health Workforce, Physicians Distribution

\section{Resumen}

El 1 de agosto de 2019, el Presidente Bolsonaro y su Ministro de Salud lanzaron el Programa Médicos pelo Brasil (Programa Médicos por el Brasil) que reemplazará al Programa Más Médicos (Programa Mais Médicos). El propósito de este artículo es contribuir a un análisis de esta última propuesta de política de salud de la Atención Primaria de Salud en el contexto del Mais Médicos y otras políticas de desarrollo y calificación de la Estrategia de Salud de la Familia (ESF) en el país, desde 1994 hasta 2019.

Palabras clave: Atención Primaria de Salud, Estrategia de Salud Familiar, Política de Salud, Fuerza Laboral en Salud, Distribución de Médicos

Como citar: Anderson MIP. Médicos pelo Brasil e as políticas de saúde para a Estratégia Saúde da Família de 1994 a 2019: caminhos e descaminhos da Atenção Primária no Brasil. Rev Bras Med Fam Comunidade. 2019;14(41):2180. https://doi.org/10.5712/rbmfc14(41)2180
Autor correspondente: Maria Inez Padula Anderson. E-mail: inezpadula@yahoo.com.br Fonte de financiamento: declara não haver.

Parecer CEP: não se aplica.

Procedência e revisão por pares: revisado por pares. Recebido em: 27/08/2019. Aprovado em: 03/09/2019. 


\section{Introdução}

No dia 1 de agosto de 2019, através da Medida Provisória no 890, o presidente Jair Bolsonaro e seu ministro da Saúde, Luiz Henrique Mandetta, lançam o Programa Médicos pelo Brasil (PMPB) como aquele que, segundo eles, substituirá o Programa Mais Médicos (PMM) para o Brasil, instituído em 2013, no governo da presidente Dilma Rousseff. Na cerimônia de lançamento, o presidente da República justificou a necessidade de mudança porque o Mais Médicos seria na realidade uma estratégia para formar "núcleos de guerrilha" no Brasil. E questionou a eficácia do programa, usando como exemplo os médicos cubanos que atuaram no Brasil, tecendo os seguintes comentários: "Se os cubanos fossem tão bons assim, teriam salvado a vida de (Hugo) Chávez, não deu certo". ' Vale dizer que o ex-presidente da Venezuela morreu, em 2013, em decorrência de um câncer na região pélvica.

Será o Médicos pelo Brasil, esta mais recente proposta de política de saúde, mais ou menos adequada do que a que a antecedeu, o Mais Médicos? Quais seriam os parâmetros de análise?

O propósito deste artigo é contribuir para uma análise das mais recentes propostas de política de saúde no âmbito da Atenção Primária à Saúde (APS) - o Saúde na Hora e o Médicos pelo Brasil - no contexto do Mais Médicos e das demais políticas de desenvolvimento e qualificação da Estratégia Saúde da Família (ESF) no país no período de 1994 a 2019, sem a pretensão de incluir todas as dimensões e ações que fizeram e fazem parte desta história.

Para falar da $\mathrm{ESF}^{2}$ e situá-la na organização do sistema de saúde brasileiro, vale recordar que o Sistema Único de Saúde (SUS) nasceu em 1988, há somente 31 anos, após 100 anos da constituição da República. Nestes 100 anos, ter acesso a serviços de saúde era um privilégio para poucos, praticamente restrito à parcela da população urbana vinculada ao mercado formal de trabalho.

Para chegar até o SUS, que consagrou a saúde como um direito de cidadania e um dever do estado, foi necessário um forte movimento em prol de uma reforma sanitária, que se desenvolveu nesse cenário de luta contra as desigualdades sociais. Assim, o SUS só se tornou possível com a redemocratização do Brasil, após 21 anos de ditadura militar.

Vale chamar a atenção para o fato de que o SUS, desde o princípio, sofre cronicamente com um orçamento inferior ao necessário para o desempenho das suas funções. Ao lado disso, observa-se ainda uma distribuição iníqua de seus recursos em benefício do setor hospitalar e da iniciativa privada, de tal modo que grande parte dos recursos da saúde no país acabam desviados para atender direta e/ou indiretamente os interesses dos prestadores privados de serviço.

Qual era o modelo assistencial dominante à época da implantação do SUS? Qual era a estrutura da rede assistencial e a natureza dos serviços dispensados à população? A medicina hospitalar e a medicina ambulatorial de especialidades como cardiologia, ortopedia, neurologia, oftalmologia e outras dominavam o cenário, tanto da assistência quanto da formação na área da saúde. AAPS era basicamente restrita aos Postos de Saúde que, em sua grande maioria, prestavam serviços relacionados a pacotes assistenciais e voltados para uma seleção de problemas de saúde; além disso, assistência à gestante, puericultura básica e vacinação. 
Assim, o SUS herdou uma considerável rede de grandes ambulatórios especializados e hospitais públicos que, também, já eram subfinanciados e insuficientes, além de inadequados. Ou seja, o SUS, pautado nos princípios da universalidade, integralidade e equidade, teve, desde o seu princípio, que disputar com o modelo biomédico e hospitalocêntrico de prestação de serviços, que, não por casualidade, é mais afinado aos interesses e às leis do mercado e da indústria da saúde.

Com o objetivo de implementar e desenvolver a Atenção Primária, a perna do sistema praticamente inexistente até há 25 anos, o Ministério da Saúde adotou a partir de 1994 o Programa Saúde da Família (PSF), que passou a ser reconhecido como uma política de estado, definida como "Estratégia Saúde da Família" (ESF), há somente 13 anos atrás, na gestão do então ministro José Gomes Temporão.

Nessa época, publicou-se o que deve ser considerado um marco histórico para a consolidação nacional da ESF, que foi a Política Nacional de Atenção Básica de 2006 (PNAB), alterando e revogando dezenas de Portarias existentes até então que favoreciam a fragmentação do olhar e a fragmentação do cuidado neste nível do sistema. Em 2008, para ampliar a resolutividade das ações e serviços de atenção básica, foram implementados os Núcleos de Apoio à Saúde da Família (NASF) formados por profissionais de saúde das mais diferentes áreas e especialidades. ${ }^{3}$

Para que a ESF pudesse se desenvolver de forma qualificada em um país de dimensões continentais, havia que se enfrentar grandes desafios e obstáculos: (a) uma cultura hospitalocêntrica e de valorização das subespecialidades, como forma de prestação idealizada de cuidados médicos; (b) uma concepção equivocada de que a APS é um cenário no qual se pratica uma medicina pobre para pobres; (c) a falta de recursos humanos qualificados para o trabalho na APS e a insuficiência de aparelhos formadores, desde a graduação até a pós-graduação nesta área; (d) infraestrutura física e funcional inadequada das unidades de saúde; (e) gerência em saúde pouco qualificada para o desenvolvimento satisfatório dos processos de trabalho no nível da ESF; (f) visão gerencial imediatista criando resistências para assumir e desenvolver estratégias de médio e longo prazo, ou seja, superando os 4 anos de gestão.

A ESF, além de seguir os princípios do SUS, deve realizar as sete dimensões da APS: (a) promover o acesso e o primeiro contato ao sistema de saúde e garantir uma (b) assistência longitudinal, (c) integral e (d) coordenada do cuidado em saúde, efetivando-as através de três atributos estruturantes: (a) orientação familiar: pela necessidade de considerar na avaliação das necessidades individuais de saúde o contexto familiar e seu potencial de cuidado e, também, de ameaça à saúde, incluindo o uso de ferramentas de abordagem familiar; (b) orientação comunitária: reconhecimento das necessidades de saúde da comunidade adscrita com a realização de diagnóstico comunitário, com dados epidemiológicos, através de contato direto com a respectiva população do território, visando seu empoderamento e corresponsabilidade sanitária, bem como sua participação no planejamento e a avaliação conjunta dos serviços; (c) competência cultural: adaptação dos profissionais de saúde às características culturais da população, visando promover uma comunicação dialógica e respeitosa com a comunidade.

Desde sua implementação, a ESF alcançou resultados expressivos, saindo de uma cobertura de cerca de 10\% em 1998 para aproximadamente 74\% em maio de 2019, alcançando mais de 134 milhões de brasileiros. Aumentou de forma inquestionável o acesso da população ao sistema de saúde e trouxe 
mudanças significativas nos indicadores de saúde, entre elas: a diminuição das taxas de mortalidade infantil e de internações por condições sensíveis à APS, assim como o aumento da cobertura pré-natal, e na redução dos gastos hospitalares. ${ }^{2-4}$

\section{Notas sobre políticas adotadas para a implementação e o desenvolvimento da atenção primária à saúde no Brasil - 1996-2016}

Ao analisar a trajetória histórica das ações governamentais assumidas desde a implantação do PSF, em 1994, é possível identificar que diversas medidas foram adotadas desde então pelas diferentes gestões do Ministério da Saúde, visando o enfrentamento multidimensional dos desafios multifatoriais anteriormente assinalados.

Uma das primeiras iniciativas do Ministério da Saúde visando à expansão e qualificação básica inicial do PSF foi o lançamento, em dezembro de 1996, de um edital público para a implantação de Polos de Capacitação, Formação e Educação Permanente de Pessoal para a Saúde da Família. ${ }^{5}$ O objetivo era buscar atender às necessidades de formação e desenvolvimento da força de trabalho para a atenção primária. As atividades e ações dos polos se deram principalmente através de articulações interinstitucionais, entre universidades e secretarias municipais e estaduais de saúde, realizadas sob a forma de convênios ou consórcios.

Dessa época, um dos produtos mais relevantes foi a elaboração e a aplicação dos Cursos Introdutórios ao Saúde da Família que visavam capacitar minimamente os profissionais de saúde para o desenvolvimento das ações esperadas de serem realizadas no novo modelo assistencial. Com a troca de governo ao final de 2002, os antigos polos foram extintos e uma nova política de educação permanente surgiu, com a criação dos novos Polos de Educação Permanente em Saúde (Polo-EP), no início de 2004, descaracterizando e descontinuando muitas das iniciativas e processos iniciados até então e focados na ESF. ${ }^{5}$

Diversas outras medidas se seguiram abrangendo desde a revisão e mudança da estrutura organizacional do próprio Ministério da Saúde até o desenvolvimento de outros programas e estratégias voltadas à formação em saúde no nível da graduação e da pós-graduação e também incentivos políticos e financeiros aos municípios para o desenvolvimento da Atenção Primária.

No que diz respeito especificamente à estrutura organizacional do Ministério da Saúde, o SUS, desde a sua criação, sempre enfrentou desafios relacionados à evidente discrepância entre as necessidades e as ofertas de recursos humanos para atender às necessidades de saúde da população brasileira. Isto porque, historicamente, sempre coube ao Ministério da Educação definir as políticas relacionadas à formação na área da saúde, sem que estas políticas estivessem afinadas às necessidades do sistema, muitas vezes, ao contrário.

Isto representava um relevante problema de gestão, que passa a ganhar uma nova perspectiva de solução quando, em 2003, o Ministério da Saúde cria a Secretaria de Gestão do Trabalho e da Educação na Saúde (SGTES). ${ }^{6}$ O principal objetivo da SGTES era mobilizar ações gerenciais no campo do trabalho e da formação, visando valorizar e qualificar os profissionais da área da saúde em conformidade com as necessidades de saúde da população, buscando equacionar os problemas existentes na área e definir políticas, articulando ações do Ministério da Educação e do Trabalho, o Legislativo e a Sociedade Civil e, também, as demandas das instâncias federativas gestoras do sistema. A criação desta secretaria permitiu 
a implementação de uma série de ações que viriam a afetar positivamente a formação de profissionais mais adequados ao perfil de morbimortalidade da população brasileira. ${ }^{6}$

No contexto da criação da SGTES, diferentes iniciativas promovidas pelo Ministério da Saúde são levadas a cabo para desenvolver a ESF e o próprio SUS no seu conjunto. Algumas merecem destaque especial no contexto da qualificação e expansão da ESF:

1) O Pró-saúde, Programa Nacional de Reorientação da Formação Profissional em Saúde ${ }^{7}$ é lançado em 2005, representando, possivelmente, a primeira iniciativa conjunta do Ministério da Saúde com o Ministério da Educação, através da SGTES, em conjunto com a Secretaria de Educação Superior (SESu) e com o Instituto Nacional de Estudos e Pesquisas Educacionais Anísio Teixeira (INEP). Foi desenvolvido para aproximar a formação de graduação no país às necessidades da ESF, contribuindo para o desenvolvimento de uma escola comprometida às necessidades de saúde população brasileira e ao SUS.

2) O Telessaúde ${ }^{8}$ - integrando ensino e serviço por meio de ferramentas de tecnologias da informação, para promover a Teleassistência e a Teleducação foi lançado em 2007, em nível nacional. Dirigido inicialmente ao desenvolvimento dos profissionais da ESF, foi implementado através de parcerias com universidades públicas, quando foram criados nove núcleos de Telessaúde em universidades nos estados de todas as regiões do Brasil.

3) O Programa Nacional de Apoio à Formação de Médicos Especialistas em Áreas Estratégicas (Pró-Residência Médica), ${ }^{9}$ lançado em 2009, pelo Ministério da Saúde, com o objetivo de apoiar a formação especialistas em regiões e áreas prioritárias para o SUS. Como modalidades de indução, foram implementadas duas ações principais: (a) financiamento de bolsas de residência para vagas novas em programas prioritários que estejam de acordo com as políticas de saúde do SUS; (b) apoio à criação, ampliação e requalificação de programas de residência médica prioritários por meio do apoio matricial interinstitucional.

4) O Programa de Educação pelo Trabalho para a Saúde (PET-Saúde), de março de 2010, ${ }^{10}$ do Ministério da Saúde, para qualificação dos profissionais da saúde, em conjunto com a formação de estudantes de graduação da área da saúde em ações de práticas de iniciação ao trabalho, contribuindo para o fortalecimento das ações de integração ensino-serviço-comunidade, envolvendo a pesquisa, a extensão universitária e a participação social.

5) O estabelecimento do Sistema Universidade Aberta do SUS (UNA-SUS), ${ }^{11}$ em dezembro de 2010, visando atender inicialmente às necessidades de capacitação e educação permanente dos profissionais que atuam na ESF, cobrindo 98\% dos municípios brasileiros, sendo que aproximadamente $50 \%$ dos profissionais capacitados são oriundos da Atenção Primária.

6) Residência de Medicina de Família e Comunidade - Apoio à gestão municipal. ${ }^{12}$ Em dezembro de 2012, foi publicada a Portaria no 3.147/2012 para incentivar os municípios a desenvolverem o Programa de Residência de Medicina de Família e Comunidade na sua Rede de Atenção à Saúde objetivando, com acompanhamento de preceptoria, as equipes de saúde da família, com recomendação aos municípios para a equiparação da bolsa à média salarial do médico de saúde da família a partir do recebimento do PAB variável. 
7) O Programa de Requalificação de Unidades Básicas de Saúde, Requalifica UBS, ${ }^{13}$ instituído em 2011, como uma das estratégias do Ministério da Saúde para a estruturação e o fortalecimento da Atenção Básica, através da qualificação da estrutura física das unidades básicas de saúde, criando incentivos financeiros para a reforma, ampliação e construção de UBS envolvendo também ações para a informatização dos serviços e a qualificação da atenção à saúde desenvolvida pelos profissionais da equipe.

8) Aestratégia Consultório na Rua, ${ }^{14}$ instituída pela Política Nacional de Atenção Básica, em 2011, visou ampliar o acesso da população em situação de rua aos serviços de saúde para esse grupo populacional, que se encontra em condições de vulnerabilidade e com os vínculos familiares interrompidos ou fragilizados.

9) O Programa Nacional de Melhoria do Acesso e da Qualidade da Atenção Básica (PMAQ), ${ }^{15}$ lançado em 2011, com o objetivo incentivar os gestores e as equipes a melhorar a qualidade dos serviços de saúde oferecidos na APS, através um conjunto de estratégias de qualificação, acompanhamento e avaliação do trabalho das equipes de saúde.

\section{Provisão e fixação de profissionais na APS em áreas remotas e de difícil acesso}

Apesar de todas essas iniciativas, a provisão e a fixação de profissionais para a prática da APS em municípios periféricos, inclusive nas periferias das grandes cidades, um dos mais graves e crônicos problemas do Brasil, ainda se mantinha sem solução adequada. Relacionado a esta questão, e mesmo antes da configuração da ESF, o Brasil já havia ensaiado algumas iniciativas como: o Programa de Interiorização das Ações de Saúde e Saneamento (PIASS - 1976); o Programa de Interiorização do Sistema Único de Saúde (PISUS - 1993). Já no início da década de 2000, é levado a cabo o Programa de Interiorização do Trabalho em Saúde (PITS - 2001), criado na perspectiva de levar 300 médicos e 300 enfermeiros para o interior do País, atendendo 142 municípios das regiões Norte, Nordeste, Centro-Oeste e Sudeste visando impulsionar a reorganização da atenção básica à saúde. ${ }^{16}$

Em 2011, o governo lança o Programa de Valorização dos Profissionais da Atenção Básica (PROVAB), ${ }^{17}$ em especial da Estratégia de Saúde da Família, nos municípios com maior percentual de pobreza, em áreas remotas e de difícil acesso, visando o provimento e fixação de profissionais e áreas com populações em maior vulnerabilidade.

Estes programas, no seu conjunto, contribuíram para o encaminhamento do problema, mas nenhum conseguiu fazê-lo na magnitude necessária para suprir a demanda dos municípios. Na pretensão de implementar uma política mais robusta para sanar no curto e no médio prazo o problema da oferta de serviços médicos em áreas remotas e socioeconomicamente vulneráveis, o Programa Mais Médicos $(\mathrm{PMM})^{18}$ foi instituído em outubro de 2013, com a Medida Provisória no 621 , posteriormente convertida na Lei $\mathrm{n} \times 12.871,{ }^{19}$ em outubro de 2013. Foi baseado em evidências que apontavam para um cenário de escassez de médicos no País, sobretudo na Atenção Primária à Saúde (APS), tendo sido estruturado em três eixos: 
a) Infraestrutura da Atenção Básica em Saúde;

b) Organizacional ou Educacional; e

c) Provimento Emergencial, denominado Projeto Mais Médicos para o Brasil (PMMB), visando, entre outros objetivos, diminuir a carência de médicos nas regiões prioritárias e reduzir as desigualdades no acesso à saúde. A intencionalidade dessa ação era atender à população de forma imediata, até que as ações com foco na ampliação da formação do médico expressassem resultados. ${ }^{20}$

Dentre os principais objetivos do Mais Médicos, estava o de consolidar a ESF e o provimento de médicos no curto, médio e longo prazos, incluindo naquele momento, além dos municípios remotos e mais vulneráveis, as populações mais fragilizadas dos grandes centros urbanos. Considerando os desafios listados anteriormente para implementar e consolidar a ESF no país, o PMM pode ser considerado um programa que abrange as principais dimensões envolvidas nestes desafios, seguindo recomendações internacionais, ${ }^{19,20}$ a saber:

1) Reordenação da oferta de cursos de Medicina e de vagas para residência médica, priorizando regiões de saúde com menor relação de vagas e médicos por habitante e com estrutura de serviços de saúde em condições de ofertar campo de prática suficiente e de qualidade para os alunos;

2) Mudanças na formação da graduação em medicina no Brasil, instando à efetiva implantação das diretrizes curriculares nacionais definidas pelo Conselho Nacional de Educação (CNE), e pontuando que ao menos $30 \%$ da carga horária do internato médico na graduação deva ser desenvolvida na Atenção Primária e em Serviço de Urgência e Emergência do SUS, em 2 anos de internato;

3) Incremento da formação pós-graduada, em especial, os Programas de Residência Médica que deveriam, até 2018 , ofertar anualmente vagas equivalentes ao número de egressos dos cursos de graduação em Medicina do ano anterior;

4) Expansão das vagas de Residência em Medicina de Família e Comunidade, sendo prevista a criação de 12 mil vagas para formação de especialistas em nível de residência em MFC até 2020;

5) Aperfeiçoamento dos médicos participantes do Mais Médicos através da oferta de curso de especialização por instituição pública de educação superior, envolvendo atividades de ensino, pesquisa e assistência mediante integração ensino-serviço, sob a orientação de médicos supervisores e tutores;

6) Incentivo financeiro para os médicos integrantes do Projeto, incluindo bolsas nas seguintes modalidades: I - bolsa-formação; II - bolsa-supervisão; e III - bolsa-tutoria;

7) Adequação das unidades básicas de saúde com qualidade de equipamentos e infraestrutura, a serem definidas nos planos plurianuais. Neste tópico, o Ministério da Saúde investiu, até 2016, $\mathrm{R} \$ 5,5$ bilhões para a construção de 6 mil novas Unidades da ESF, reforma e ampliação de 11,8 mil unidades já existentes e compra de equipamentos para 5 mil unidades em obras de reforma e infraestrutura para as unidades da ESF. ${ }^{21}$ 
Como municípios elegíveis para adesão ao provimento emergencial proposto pelo PMMB, consideraram-se as regiões prioritárias para o SUS: áreas de difícil acesso, de difícil provimento de médicos ou que possuíssem populações em situação de vulnerabilidade, definidas com base nos critérios estabelecidos pela Portaria no 1.377/GM/MS. ${ }^{22}$ Esses previram, pelo menos, uma das seguintes condições: a) ter o município $20 \%$ ou mais da população vivendo em extrema pobreza, com base nos dados do Ministério do Desenvolvimento Social e Combate à Fome; b) estar entre os 100 municípios com mais de 80.000 habitantes com os mais baixos níveis de receita pública per capita e alta vulnerabilidade social de seus habitantes; c) estar situado em área de atuação de Distrito Sanitário Especial Indígena; d) estar nas áreas referentes aos $40 \%$ dos setores censitários com os maiores percentuais de população em extrema pobreza dos municípios. ${ }^{20-24}$

Uma das especificidades do PMM foi a supervisão acadêmica in loco, um dos eixos educacionais do PMMB, que tinha por finalidade o fortalecimento da política de educação permanente, por meio da integração ensino-serviço no componente assistencial da formação dos médicos participantes do PMM. A supervisão é realizada por tutores (professores de Faculdades de Medicina de universidades públicas) na proporção de 1 tutor e 10 supervisores para cada 100 médicos participantes. ${ }^{22,23}$

O Plano Nacional de Formação de Preceptores (PNFP) ${ }^{25}$ foi implementado como parte integrante deste eixo de formação do Programa Mais Médicos, com o objetivo central de subsidiar e assegurar instrumentos para o processo de expansão de vagas de residência em Medicina de Família e Comunidade de modo a assegurar a universalização do acesso a esta modalidade de pós-graduação.

Entre os principais objetivos, estão: (a) fortalecer a atenção primária à saúde no País; (b) capacitar o médico em formação na área de Medicina de Família e Comunidade como multiplicador da formação e aperfeiçoamento na Atenção Primária; (c) fortalecer a Política de Educação Permanente em Saúde com a integração dos profissionais médicos ao modelo de formação e aperfeiçoamento ensino-serviço; (d) estimular a realização de pesquisas em saúde no campo da Atenção Primária.

Em 2015, 18.240 profissionais do PMM estavam presentes em 81\% dos municípios brasileiros, em todas as 27 capitais de estados, em todos os 34 Distritos Sanitários Especiais Indígenas (DSEI), em 87\% dos municípios de regiões metropolitanas e em $82 \%$ dos municípios com maior proporção de pessoas em extrema pobreza, cobrindo 63 milhões de brasileiros em condições de elevada vulnerabilidade. . $^{23,26}$

Além da expansão, houve substituição das equipes, sugerindo que o Mais Médicos contribuiu para fixação de profissionais e redução da rotatividade, bem como para inserção do médico nas equipes incompletas ou irregulares. ${ }^{22,26}$ São relevantes também os impactos do Mais Médicos nos indicadores de saúde: antes da implementação do programa, as taxas de internação por condições sensíveis à atenção primária já vinham diminuindo (em 7,9\% de 2009 a 2012). No entanto, essa redução foi mais importante após o programa $(9,1 \%$ entre 2012 e 2015$) .^{23}$

Mais recentemente e ainda no contexto dos objetivos do Mais Médicos, houve a criação do Mestrado Profissional em Saúde da Família ProfSaúde, ${ }^{27}$ lançado em 2016, após ser concluída sua elaboração por equipes de universidades públicas que compreendeu diferentes estados brasileiros. Constitui um programa de pós-graduação stricto sensu, reconhecido pela Coordenação de Aperfeiçoamento de Pessoal de Nível Superior (CAPES) do Ministério da Educação. Surge como uma estratégia para formar os profissionais 
necessários para atender a expansão da graduação e pós-graduação, bem como, a educação permanente de profissionais de saúde, apoiando a consolidação do modelo da Estratégia de Saúde da Família mediante o fortalecimento de conhecimentos relacionados à APS, à gestão e à educação em saúde.

Estes profissionais deverão atuar como preceptores para graduação e residência médica em Saúde da Família, com o intuito de contribuir para a melhoria do atendimento dos usuários do SUS. O Mestrado Profissional em Saúde da Família, o Profsaúde, é efetivado por meio da parceria de 18 universidades públicas.

No campo da produção cientifica, apesar do curto período de tempo desde sua implementação, o PMM traz uma relevante contribuição na área da APS no Brasil, especialmente focalizando a questão do provimento de médicos: no período de 2013 a junho de 2017 foram identificadas pelo menos 289 publicações, sendo 44 em formato acadêmico (tese ou dissertações), 40 pesquisas cadastradas e 195 artigos. ${ }^{21,23}$

Pode-se dizer que o Mais Médicos, ainda que apresente alguns problemas passíveis de solução, se revela uma estratégia multidimensional com potencial para apoiar a estruturação do SUS e da APS, uma vez que concilia intervenções objetivas (provimento de médicos) com ações que visam o desenvolvimento de capacidades locais, bem como a formação em saúde e produção de conhecimentos no campo da ESF, articulando diferentes níveis dos setores da saúde e da educação. Além disso, tem enfrentado a lei da oferta e da procura do mercado médico, através do direcionamento que o Ministério da Saúde e o Ministério da Educação exercem para a regulação da força de trabalho médica no Brasil. ${ }^{16,20,22,23}$

Em estudo sobre a percepção de gestores municipais sobre o PMM, realizada em $2017,{ }^{28}$ estes reconheciam avanços importantes nas melhorias na Atenção à Saúde, no acesso à rede e à humanização do cuidado. No entanto, apontaram que a sustentabilidade dessa política estava atrelada à implementação e manutenção das medidas estruturantes do PMM, tais como ampliação de vagas e criação de novos cursos de Medicina, políticas de cargos, carreira e salários para profissionais da saúde, melhorias na infraestrutura das unidades de saúde.

\section{AS PNABs 2006 e 2011 e o desenvolvimento da Estratégia Saúde da Família}

A PNAB de 2006 alterou o conceito de programa SAÚDE DA FAMILIA para o de ESTRATÉGIA SAÚDE DAFAMILIA. A partir desta nova formulação se passou a considerar como fundamental o apoio do nível federal à formação de pessoal para a Atenção Primária, seja por meio da reformulação dos cursos de graduação em saúde, como pela ampliação dos programas de residência médica e multiprofissional voltados para o trabalho na APS.

APNAB de $2011^{29}$ reforçou a incorporação dos Núcleos de Apoio à Saúde da Família (NASF), criados em 2008, ampliando o espectro de profissionais que atuam na Atenção Primária e as possibilidades de intervenção e a capacidade de resolver problemas de saúde da população. Um avanço nesta PNAB foi a possibilidade de que até 8 horas semanais da carga horária dos membros das equipes pudesse ser dedicada a cursos de especialização em Saúde da Família, residência de Medicina de Família e de Comunidade e/ou multiprofissional, bem como atividades de educação permanente e apoio matricial; também poderia ser utilizada em serviços da rede de urgência do município. 


\section{Conjuntura e políticas de saúde no Brasil nos governos Temer e Bolsonaro - 2017 - 2019}

Em 2016, após um intenso processo político questionado por muitos juristas ${ }^{30}$ a presidente Dilma Rousseff é afastada do cargo e assume a presidência da República Michel Temer. Verifica-se, então, uma reorganização das forças conservadoras no Brasil, que vem sendo acompanhada do recrudescimento de políticas que vão na direção da redução da dimensão pública do Estado, ampliando a participação do setor privado, afetando os direitos trabalhistas e previdenciários. ${ }^{31}$

Na área da saúde, e como uma das primeiras medidas do governo Temer, está o congelamento por 20 anos os gastos nas áreas da saúde e educação através da PEC 241/2016, transformada em Emenda Constitucional no 95 de 15/12/2016. ${ }^{32}$ Vale recordar que, logo após a posse do então ministro da Saúde, Ricardo Barros, este declarou ${ }^{33}$ que o SUS não cabia no orçamento da nação, manifestando-se favorável à criação de Planos Populares de Saúde com cobertura reduzida no campo da Atenção Primária, ${ }^{34}$ declaração que, naturalmente, atendia aos interesses das empresas privadas de saúde, que, segundo a mídia, sustentavam ao longo do tempo a vida política do próprio ministro da saúde..$^{35-37}$

Configura-se, assim, um terreno propício para dar prosseguimento à desconstrução do SUS, "cujo financiamento jamais alcançou um patamar de suficiência e estabilidade, ao passo que as empresas privadas de planos de saúde sempre foram objeto de fortalecimento, por meio da destinação de incentivos financeiros contínuo" ${ }^{38}$

PNAB 2017 - Em setembro de 2017, foi publicada uma nova PNAB, ${ }^{39}$ que provocou crítica de organizações historicamente vinculadas à defesa do SUS, como a Associação Brasileira de Saúde Coletiva (Abrasco), o Centro Brasileiro de Estudos de Saúde (Cebes) e a Escola Nacional de Saúde Pública (Ensp). Em nota conjunta, as três instituições denunciaram, entre outras coisas, a revogação da prioridade dada à ESF, em um contexto de retração do financiamento da saúde, demonstrando preocupação com retrocessos em relação à construção de uma APS integral, que vinha sendo construída sob a lógica da ESF. ${ }^{40}$

Esta PNAB pareceu ceder à pressão e aos interesses neoliberais, já evidenciados desde o início do governo Michel Temer, acabando por permitir maior flexibilização na implementação de modelos de APS, retirando o caráter indutor e propositivo das políticas, pressionando pela desconstrução da ESF, do compromisso com sua expansão e do sistema público: ${ }^{40}$ a relativização da cobertura universal, a definição de padrões distintos de serviços, com recomposição das equipes e a reorganização do processo de trabalho na APS; a segmentação do acesso ao cuidado; a desvinculação das equipes dos territórios; a desqualificação do trabalho de ACS e ACE, acentuando o caráter utilitarista de suas atividades e o reforço à privatização e, não menos importante, as consequências do possível descompromisso dos gestores com a oferta universal dos serviços de APS.

\section{Governo Bolsonaro: Saúde na Hora e o Programa Médicos pelo Brasil}

As políticas implementadas até agora no governo Bolsonaro demonstram seguir a mesma cartilha do governo Temer no caminho da privatização da Saúde e desvalorização da ESF. Ainda no mês de julho de 2019, durante atividade no 15 Congresso Brasileiro de Medicina de Família e Comunidade, o Secretário de Atenção Primária do Ministério da Saúde se manifestou publicamente dizendo que o SUS não é para todos, contrariando os próprios princípios deste sistema e a Constituição do Brasil. 
No dia 15 de maio de 2019, é lançado, no âmbito da APS, com grande alarme, o Programa Saúde na Hora ${ }^{41}$ que apoia financeiramente os municípios que o adotarem. Este programa aponta para a transformação das Unidades de Saúde da Família, nos municípios de médio e grande porte, em unidades de pronto-atendimento uma vez que um dos objetivos desta medida é "reduzir o volume de atendimentos em unidades de pronto atendimento e emergências hospitalares conjugado a um funcionamento mínimo da unidade de 60 (sessenta) horas semanais, sendo 12 (doze) horas diárias ininterruptas, em dias úteis, de segunda-feira a sexta-feira; ou, 11 (onze) horas diárias ininterruptas, em dias úteis, de segunda a sextafeira, e 5 (cinco) horas diárias aos sábados ou domingo". ${ }^{41}$

Também estão previstas no "Saúde na Hora" a possibilidade de redução da carga horária do médico, comprometendo a referência do território adscrito por cada equipe da ESF. Além disso, apesar de parecer o contrário, não aumenta a concentração de médicos e outros profissionais de saúde de modo equitativo no processo de trabalho, uma vez que o horário de concentração de busca por atendimento não se distribui uniformemente durante o período. Ou seja, o Saúde na Hora, desconstrói o processo de trabalho da ESF, desorganiza ações de saúde, deixando em aberto necessidades de saúde fundamentais, considerando o perfil de morbimortalidade da população.

No dia 1 de agosto de 2019, às vésperas da XVI Conferência Nacional de Saúde, o governo apresenta o Programa Médicos Pelo Brasil (MPB), ${ }^{42}$ por meio da Medida Provisória 890. A análise deste Programa evidencia que ele se constitui como mais uma iniciativa de provimento médico, buscando ampliar a oferta de serviços em locais de difícil provimento ou de alta vulnerabilidade, embora refira também que se dedicará a formar especialistas em Medicina de Família e Comunidade, mas por meio de cursos de especialização, cuja tutoria pode ficar a cargo de clínicos.

Neste contexto, um primeiro grave problema se configura: o Médicos pelo Brasil não destina qualquer comentário sobre a formação por meio de Programas de Residência Médica, padrão-ouro na formação de especialistas em qualquer área da medicina, desconsiderando o relevante investimento que se fez nos últimos 13 anos de ampliação do número de vagas dos Programas de Residência de Medicina de Família e Comunidade, que atinge na atualidade cerca de 5.500 vagas, mas que ainda carecem de políticas indutoras para que seja otimizada sua ocupação.

Também, não se refere às outras dimensões que foram previstas no Mais Médicos ${ }^{43}$ e citadas anteriormente neste artigo, deixando dúvidas e preocupações com os destinos das políticas públicas que incentivam a participação e o envolvimento das universidades públicas no desenvolvimento da ESF, assim como dos cursos de especialização e de desenvolvimento profissional contínuo para profissionais da ESF promovidos a UNASUS, assim como as ações do Telessaúde e do Pró-residência no mesmo sentido; das políticas de incentivo à criação e apoio à implementação de PRMFCs, do mestrado profissional ProSaúde, enfim, de todo um conjunto de ações vinculadas para a qualificação progressiva da ESF e da APS no Brasil.

Um outro aspecto que causa espécie no Médicos pelo Brasil é sobre o conceito de APS que ele encerra, contrariando os preceitos universalmente preconizados, bem como os consagrados pela ESF. O MPB reduz drasticamente o escopo de ações da APS, ao suprimir o eixo estruturante das ações da ESF relacionados aos atributos de orientação familiar, orientação comunitária e competência cultural - atributos estes que balizam a forma como a prestação de cuidados em saúde deve ser feita na APS. 
Mas há mais aspectos a trazer preocupações: esta proposta traz no seu interior, aos moldes de um Cavalo de Troia, o deslocamento da gestão pública para o âmbito privado: a MP propõe a criação da ADAPS - Agência para o Desenvolvimento da Atenção Primária à Saúde". Esta ADAPS constitui "serviço social autônomo na forma de pessoa jurídica de direito privado com a finalidade de promover, em âmbito nacional, a execução de políticas da atenção primária à saúde".

Essa transferência da execução de uma política pública para uma agência privada - com representante do setor privado em detrimento do Controle Social na sua estrutura organizacional - por meio de contrato, aponta claramente na direção da privatização da APS/ESF e, do próprio SUS.

Um aspecto que poderia ser considerado um avanço nesta proposta é aquele que aponta para a possibilidade de contratação, pela ADASP, via CLT, dos médicos que forem aprovados no curso de especialização, devendo os mesmos permanecer nas USF em que realizaram a formação. A contratação via CLT propõe quatro níveis salariais, com progressão a cada três anos de participação no programa, além de gratificação por desempenho vinculada ao alcance de indicadores de qualidade de atendimento e satisfação das pessoas atendidas.

Entretanto, com as mudanças que vêm ocorrendo nas políticas de recursos humanos incluindo as reformas da Previdência Social, as mudanças negativas na legislação do trabalho, ${ }^{44}$ e a própria extinção do Ministério do Trabalho deixam estas perspectivas em suspenso, mesmo porque terão seu início previsto para o fim, ou mesmo para depois do período de tempo deste governo.

\section{Considerações finais}

A construção da Atenção Primária no Brasil, baseada nos princípios do SUS e organizada segundo as concepções da ESF, representa uma reforma institucional e cultural de grandes proporções e depende de mudanças profundas na formação em saúde e na educação médica, muitas das quais têm sido implementadas pelo governo brasileiro nos últimos 20 anos.

Entre estas mudanças, está a necessidade de redefinir a função dos níveis secundário e terciário do SUS, incluindo o papel de seus profissionais e o processo de trabalho nas unidades que os constituem. Todo este conjunto de mudanças tem afetado o status quo e provocado estranhamentos e conflitos advindos, principalmente, de grupos estabelecidos nos meios assistenciais, acadêmicos e gerenciais em todos os níveis de governo, como assinalado em um documento da OPAS ${ }^{45}$ ao estudar as oposições às reformas em prol da APS: "alguns médicos especialistas e suas associações; hospitais; a indústria farmacêutica e algumas organizações que difundem as suas ideias. Esses grupos estão entre os mais poderosos em termos de recursos e capital político e seus interesses estão frequentemente alinhados em oposição a muitos esforços de reforma da saúde".

Estas mudanças implicam também em implementar estratégias que possam promover uma mudança na perspectiva das pessoas, famílias e comunidades em relação aos serviços de saúde, de modo que passem a desejar uma abordagem mais integral à saúde considerando as dimensões biopsicossociais do processo saúde adoecimento. Aquele padrão cultural de uso do sistema de saúde foi forjado ao longo dos 
últimos 100 anos no Brasil, fundamentado em práticas de saúde de base hospitalocêntrica e de caráter biomédico, alijado de uma APS qualificada. Isto tem afetado a capacidade de a população identificar suas necessidades em saúde, criando demandas por serviços e ações mais centradas na doença, na qual se consome mais tecnologia dura, mais medicamentos e procedimentos, e, por tudo isso, é mais iatrogênica.

Neste contexto, e apesar das muitas conquistas alcançadas pela ESF, é importante que se tenha clareza que, para sua manutenção e desenvolvimento, muitos desafios ainda estão colocados, especialmente em um cenário no qual os interesses de mercado parecem estar no centro dos processos.

Para continuar avançando é, e será necessário atuar, de forma contínua e ininterrupta, superando resistências e implementando políticas públicas indutoras consistentes e sem solução de continuidade. Neste momento, o incremento de autonomia habitualmente requerido pelos gestores municipais, e que tem servido de justificativa para muitas das reformas que descaracterizam a ESF, se dá numa conjuntura de ameaças aos direitos sociais e de restrição orçamentária, com agravamento da situação de subfinanciamento do SUS. Esse contexto favorece a influência dos interesses de mercado visando a implantação de planos privados de cobertura restrita e de modelos alternativos à ESF, com resultados no mínimo questionáveis para a organização da APS.

O Brasil de 2019 se encontra em um cenário no qual os princípios democráticos estão abalados e se banaliza (ou não se identifica) o aprofundamento das iniquidades sociais. Estas iniquidades tendem a se acentuar progressivamente com a mercantilização da saúde, com a ampliação do setor privado e com a pretensão de transferência do papel do Estado nas decisões na área da saúde, como se pode depreender a partir do Programa Médicos pelo Brasil e da ADAPS.

As justificativas que podem ser apresentadas para as mudanças de rumo no seio da ESF mostramse insuficientes, e mesmo falaciosas, na medida em que suprimem do debate as análises que mostram os impactos positivos da ESF nas condições de vida e saúde da população. Esse contexto compromete o processo decisório na utilização de recursos, e favorece a influência de interesses privados visando a implantação de planos de saúde de cobertura restrita e de modelos alternativos à ESF, com resultados duvidosos para a organização da APS.

O caminho para o enfrentamento destes desvios deve ter base técnica, e sobretudo ética, na busca pela construção de uma sociedade mais justa, em que o respeito ao ser humano e as necessidades de saúde se sobreponham aos valores e às necessidades do mercado.

\section{Contribuição dos autores}

Concepção e delineamento do estudo: MIPA. Aquisição, análise e interpretação dos dados: MIPA. Redação preliminar: MIPA. Revisão crítica da versão preliminar: MIPA.

A autora aprovou a versão final e concordou com prestar contas sobre todos os aspectos do trabalho.

\section{Conflito de interesses}

Declara não haver. 


\section{Referências}

1. Lindner J, Weterman D. Bolsonaro diz que Mais Médicos tinha objetivo de formar 'núcleos de guerrilha'. O Estado de São Paulo. 2019 Ago 1 [acesso 2019 Ago 20]. Disponível em: https://saude.estadao.com.br/noticias/geral,bolsonaro-diz-que-mais-medicos-tinha-objetivode-formar-nucleos-de-guerrilha,70002950683

2. Ministério da Saúde (BR). Portaria № 648, de 28 de março de 2006. Aprova a Política Nacional de Atenção Básica, estabelecendo a revisão de diretrizes e normas para a organização da Atenção Básica para o Programa Saúde da Família (PSF) e o Programa Agentes Comunitários de Saúde (PACS). Brasília: Diário Oficial da União; 2006.

3. Pinto LF, Giovanella L. Do Programa à Estratégia Saúde da Família: expansão do acesso e redução das internações por condições sensíveis à atenção básica (ICSAB). Ciênc Saúde Coletiva. 2018;23(6):1903-14. https://doi.org/10.1590/1413-81232018236.05592018

4. da Silva EN, Powell-Jackson T. Does expanding primary healthcare improve hospital efficiency? Evidence from a panel analysis of avoidable hospitalisations in 5506 municipalities in Brazil, 2000-2014. BMJ Glob Health. 2017;2(2):e000242. https://doi.org/10.1136/ bmjgh-2016-000242

5. Aguiar RAT. A universidade e as políticas de educação permanente para a estratégia saúde da família: um estudo de caso [Tese de doutorado]. Belo Horizonte: Universidade Federal de Minas Gerais, Faculdade de Educação; 2010.

6. Magnago C, Pierantoni CR, França T, Vieira SP, Miranda RG, Nascimento DN. Política de Gestão do Trabalho e Educação em Saúde: a experiência do ProgeSUS. Ciênc Saúde Coletiva. 2017;22(5):1521-30. https://doi.org/10.1590/1413-81232017225.32962016

7. Ministério da Saúde; Ministério da Educação (BR). Programa Nacional de Reorientação da Formação Profissional em Saúde: Pró-Saúde. Brasília: Ministério da Saúde; 2007.

8. Telessaúde (MS), Uma Ação Nacional [acesso 2019 Ago 20]. Disponível em: http://telessaude.saude.ms.gov.br/portal/sobre-otelessaude-2/

9. Petta HL. Formação de médicos especialistas no SUS: descrição e análise da implementação do programa nacional de apoio à formação de médicos especialistas em áreas estratégicas (Pró-Residência). Rev Bras Educ Med. 2013;37(1):72-9.https://doi.org/10.1590/S010055022013000100011

10. Ministério da Saúde (BR). Programa de Educação pelo Trabalho para a Saúde (PET-Saúde). Brasília: Ministério da Saúde;2010. Disponível em: http://www.saude.gov.br/trabalho-educacao-e-qualificacao/gestao-da-educacao/qualificacao-profissional/44938-programa-deeducacao-pelo-trabalho-para--saude-pet-saude

11. Ministério da Saúde (BR). UNA-SUS: Universidade Aberta do SUS. Brasília: Ministério da Saúde; 2010. Disponível em: https://www. unasus.gov.br/institucional/unasus

12. Ministério da Saúde (BR). Pró-Residência Médica: Programa Nacional de Apoio à Formação de Médicos Especialistas em Áreas Estratégicas (Pró-Residência Médica) com o objetivo de apoiar a formação especialistas em regiões e áreas prioritárias para o Sistema Único de Saúde (SUS). Brasília: Ministério da Saúde; 2009. Disponível em: http://www.saude.gov.br/trabalho-educacao-e-qualificacao/ provisao-de-profissionais/pro-residencia-medica

13. Ministério da Saúde (BR), Secretaria de Atenção à Saúde, Departamento de Atenção Básica. Requalifica UBS: Manual Instrutivo. Brasília: Ministério da Saúde; 2016.

14. Ministério da Saúde (BR), Secretaria de Atenção Primária à Saúde (SAPS). Consultório na Rua. Brasília: Ministério da Saúde; 2011. Disponível em: http://aps.saude.gov.br/ape/consultoriorua/

15. Ministério da Saúde (BR), Secretaria de Atenção à Saúde, Departamento de Atenção Básica. Programa Nacional de Melhoria do Acesso e da Qualidade da Atenção Básica (PMAQ). Brasília: Ministério da Saúde;2015. Disponível em: http://www.saude.gov.br/acoese-programas/programa-de-melhoria-do-acesso-e-da-qualidade-da-atencao-basica-pmaq

16. Carvalho MS, Sousa MF. Como o Brasil tem enfrentado o tema provimento de médicos? Interface (Botucatu). 2013;17(47):913-26. https://doi.org/10.1590/1807-57622013.0403

17. Oliveira CM, Cruz MM, Kanso S, Reis AC, Lima A, Torres RMC, et al. Avaliabilidade do Programa de Valorização do Profissional da Atenção Básica (PROVAB): desafios para gestão do trabalho. Ciênc Saúde Coletiva.2015;20(10):2999-3010. https://doi.org/10.1590/1413812320152010.13322014

18. Ministério da Saúde (BR). Programa Mais Médicos: Mais Médicos para o Brasil, mais saúde para você. Brasília: Ministério da Saúde; 2015. Disponível em: http://www.maismedicos.gov.br/conheca-programa 
19. Presidência da República (BR). Lei № 12.871, de 22 de outubro de 2013. Institui o Programa Mais Médicos, altera as Leis no 8.745, de 9 de dezembro de 1993, e № 6.932, de 7 de julho de 1981, e dá outras providências. Brasília: Diário Oficial da União; 2013. Disponível em: http://www.planalto.gov.br/ccivil_03/_ato2011-2014/2013/Lei/L12871.htm

20. Carvalho VKS, Marques CP, Silva EN. A contribuição do Programa Mais Médicos: análise a partir das recomendações da OMS para provimento de médicos. Ciênc Saúde Coletiva. 2016;21(9):2773-84. https://doi.org/10.1590/1413-81232015219.17362016

21. Silva QTA, Cecílio LCO. A produção científica brasileira sobre o Projeto Mais Médicos para o Brasil (PMMB). Saúde Debate. 2019;43(121):559-75. https://doi.org/10.1590/0103-1104201912121

22. Ministério da Saúde (BR). Portaria № 1.377, de 13 de junho de 2011. Estabelece critérios para definição das áreas e regiões prioritárias com carência e dificuldade de retenção de médico integrante de equipe de saúde da família oficialmente cadastrada e das especialidades médicas prioritárias de que tratam o inciso II e o $\S 3^{\circ}$ do art. $6^{\circ}-\mathrm{B}$ da Lei № 10.260 , de 12 de julho de 2001 , no âmbito do Fundo de Financiamento Estudantil (FIES) e dá outras providências. (Redação dada pela PRT GM/MS № 203 de 08.02.2013). Brasília: Diário Oficial da União; 2011. Disponível em: http://bvsms.saude.gov.br/bvs/saudelegis/gm/2011/prt1377_13_06_2011.html

23. Organização Pan-Americana da Saúde. Programa Mais Médicos no município do Rio de Janeiro. Mais acesso, equidade e resolutividade na APS. Brasília: OPAS; 2016.

24. Organização Pan-Americana da Saúde. Folha informativa - Programa Mais Médicos. Brasília: OPAS; 2018 . [acesso 2019 Ago 20]. Disponível em: https://www.paho.org/bra/index.php?option=com_content\&view=article\&id=5662:folha-informativa-programa-maismedicos\&ltemid=347

25. Conselho Nacional dos Secretários de Saúde - CONASS (BR). Portaria Interministerial MS/MEC N. 1.618, de 30 de setembro de 2015. [acesso 2019 de Ago]. Disponível em: https://www.conass.org.br/ci-n-230-publicada-a-portaria-interministerial-n-1618-que-institui-comoeixo-do-mais-medicos-residencia-o-plano-nacional-de-formacao-de-preceptores-para-os-programas-de-residencia-na-modalidademedici/ acessada em 24 de agosto de 2019

26. Ministério da Saúde (BR), Secretaria de Gestão do Trabalho e da Educação na Saúde. Programa Mais Médicos. 2 anos: Mais Saúde Para os Brasileiros. Brasília: Ministério da Saúde; 2015.

27. Ministério da Educação; Ministério da Saúde; FIOCRUZ; ABRASCO (BR). PROFSAÚDE. Rio de Janeiro: FIOCRUZ; 2016. Disponível em: http://profsaude-abrasco.fiocruz.br/sobre-programa

28. Arruda CAM, Pessoa VM, Barreto ICHC, Carneiro FF, Comes Y, Trindade JS, et al. Percepções de gestores municipais de Saúde sobre o provimento e a atuação dos médicos do Programa Mais Médicos. Interface (Botucatu). 2017;21(Suppl 1):1269-80. https://doi.org/10.1590/1807-57622016.0235

29. Ministério da Saúde (BR). Portaria № 2.488, de 21 de outubro de 2011. Aprova a Política Nacional de Atenção Básica, estabelecendo a revisão de diretrizes e normas para a organização da atenção básica, para a Estratégia Saúde da Família (ESF) e o Programa de Agentes Comunitários de Saúde (PACS). Brasília: Diário Oficial da União; 2011.

30. Mendonça R, Puff J. Duas visões: juristas contra e a favor avaliam pedido de impeachment. BBC News. 2015 Dez 2 [acesso 2019 Ago 20]. Disponível em: https://www.bbc.com/portuguese/noticias/2015/12/151201_impeachment_2visoes_juristas_.jp

31. Morosini MVGC, Fonseca AF, Lima LD. Política Nacional de Atenção Básica 2017: retrocessos e riscos para o Sistema Único de Saúde. Saúde Debate. 2018;42(116):11-24. https://doi.org/10.1590/0103-1104201811601

32. Senado Federal (BR). Atividade Legislativa. Proposta de Emenda à Constituição № 55, de 2016 - PEC do Teto dos Gastos Públicos. Disponível em: https://www25.senado.leg.br/web/atividade/materias/-/materia/127337

33. Colucci C. Tamanho do SUS precisa ser revisto, diz novo ministro da Saúde. Folha de São Paulo. 2016 Maio 17 [acesso 2019 Ago 20] Disponível em: https://www1.folha.uol.com.br/cotidiano/2016/05/1771901-tamanho-do-sus-precisa-ser-revisto-diz-novo-ministro-dasaude.shtml

34. Agência Brasil. Planos Populares de Saúde podem estar disponíveis ainda este ano. 2017 Set 19 [acesso 2019 Ago 20]. Disponível em: http://agenciabrasil.ebc.com.br/geral/noticia/2017-09/planos-de-saude-populares-podem-estar-disponiveis-ainda-este-ano

35. Cancian N. Ministro volta a defender plano de saúde reduzido e é criticado na Câmara. Folha de São Paulo. 2016 Jul 13 [acesso 2019 Ago 24]. Disponível em: https://www1.folha.uol.com.br/cotidiano/2016/07/1791365-ministro-volta-a-defender-plano-de-saude-reduzidoe-e-criticado-na-camara.shtml

36. Colucci C. Dono de gestora de plano de saúde financiou ministro que quer rever SUS. Folha de São Paulo. 2016 Maio 17 [acesso 2019 Ago 20]. Disponível em: https://www1.folha.uol.com.br/poder/2016/05/1772087-ministro-que-defende-rever-sus-foi-financiado-por-donode-plano-de-saude.shtml 
37. Ramos M. Maior doador de campanha do ministro da Saúde é sócio de gigante de planos de saúde. Revista Época. 2016 Maio 17 [acesso 2019 Ago 24]. Disponível em: https://epoca.globo.com/tempo/expresso/noticia/2016/05/maior-doador-de-campanha-do-ministro-dasaude-e-socio-de-gigante-de-planos-de-saude.html

38. Ocké-Reis CO. Desafios da reforma sanitária na atual conjuntura histórica. Saúde Debate. 2017;41(113);365-71. https://doi. org/10.1590/0103-1104201711302

39. Ministério da Saúde (BR). Portaria № 2.436, de 21 de setembro de 2017. Aprova a Política Nacional de Atenção Básica, estabelecendo a revisão de diretrizes para a organização da Atenção Básica, no âmbito do Sistema Único de Saúde (SUS). Brasília: Ministério da Saúde; 2017. [acesso 2017 Nov 30]. Disponível em: http://bvsms.saude.gov.br/bvs/saudelegis/gm/2017/prt2436_22_09_2017.html

40. Associação Brasileira de Saúde Coletiva (Abrasco). Contra a reformulação da PNA - nota sobre a revisão da Política Nacional de Atenção Básica. Rio de Janeiro: ABRASCO; 2017 [acesso 2018 Fev 22]. Disponível em: https://www.abrasco.org.br/site/noticias/posicionamentosoficiais/contra-reformulacao-da-pnab-nota-sobre-revisao-da-politica-nacional-de-atencao-basica/29798/

41. Conselho Nacional dos Secretários de Saúde - CONASS (BR). Portaria GM N. 930, de 15 de maio de 2019. Disponível em: https://www. conass.org.br/conass-informa-n-86-publicada-a-portaria-gm-n-930-que-institui-o-programa-saude-na-hora-que-dispoe-sobre-o-horarioestendido-de-funcionamento-das-unidades-de-saude-da-familia-altera/

42. Presidência da República (BR), Secretaria-Geral, Subchefia para Assuntos Jurídicos. Medida Provisória № 890 , de 1o de agosto de 2019. Institui o Programa Médicos pelo Brasil, no âmbito da atenção primária à saúde no Sistema Único de Saúde, e autoriza o Poder Executivo federal a instituir serviço social autônomo denominado Agência para o Desenvolvimento da Atenção Primária à Saúde. Brasília: Presidência da República; 2019. Disponível em: http://www.planalto.gov.br/ccivil_03/_Ato2019-2022/2019/Mpv/mpv890.htm

43. Melo Neto AJ, Barreto DS. Programa Médicos pelo Brasil: inovação ou continuidade? Rev Bras Med Fam Comunidade. $2019 ; 14(41): 2162$. https://doi.org/10.5712/rbmfc14(41)2162

44. Almeida C; Agência Brasil. OIT inclui Brasil na lista de países suspeitos de violar direitos trabalhistas. O Globo. 2019 Jun 11. Disponível em: https://oglobo.globo.com/economia/oit-inclui-brasil-na-lista-de-paises-suspeitos-de-violar-direitos-trabalhistas-23732337

45. Organização Pan-Americana da Saúde (OPAS). Renovação da Atenção Primária em Saúde nas Américas. Washington: OPAS; 2007. 